\title{
Adolescent Girls Empowerment Program (AGEP): Mid-term findings-Brief
}

Population Council

Follow this and additional works at: https://knowledgecommons.popcouncil.org/departments_sbsr-pgy

Part of the Demography, Population, and Ecology Commons, Family, Life Course, and Society Commons, and the International Public Health Commons How does access to this work benefit you? Let us know!

\section{Recommended Citation}

"Adolescent Girls Empowerment Program (AGEP): Mid-term findings," brief. Lusaka: Population Council, 2016. 


\section{ADOLESCENT GIRLS EMPOWERMENT PROGRAM (AGEP): MID-TERM FINDINGS}

\section{INTRODUCTION}

Social isolation, economic vulnerability, and lack of access to health care and education prevent healthy transitions from childhood to adulthood, especially for vulnerable adolescent girls in developing countries. In Zambia, poor girls often are at high risk of gender-based violence, unintended pregnancy, and HIV. Many drop out of school, are unable to find employment, lack the ability to make independent decisions, and are not being reached by existing programs for young people.

The root causes of these challenges, whether they are economic poverty, regressive social and cultural gender norms, or lack of individual self-esteem, are interlinked, suggesting that solutions should be multi-sectoral as well.

Many programs $\mathrm{s}^{1,2,3}$ that help girls build social, economic and health assets have been effective in different parts of the world. By acquiring skills to navigate family, sexual relationships, health care, education and prospects for job training and a higher income, girls are more likely to maximize opportunities they encounter in life: to stay in school, delay early sex, avoid early marriage and dependency, and prevent unintended pregnancy and sexually transmitted infections, including HIV.

\section{THE ADOLESCENT GIRLS EMPOWERMENT PROGRAM (AGEP)}

The Adolescent Girls Empowerment Program (AGEP) is a four-year effort to support more than 11,000 of the most vulnerable adolescent girls in Zambia. AGEP was led by the Population Council, in partnership with the Young Women's Christian Association of Zambia (YWCA), the National Savings and Credit Bank of Zambia (Natsave) and the Government of Zambia. The program design was based on the asset-building framework which posits that if girls are able

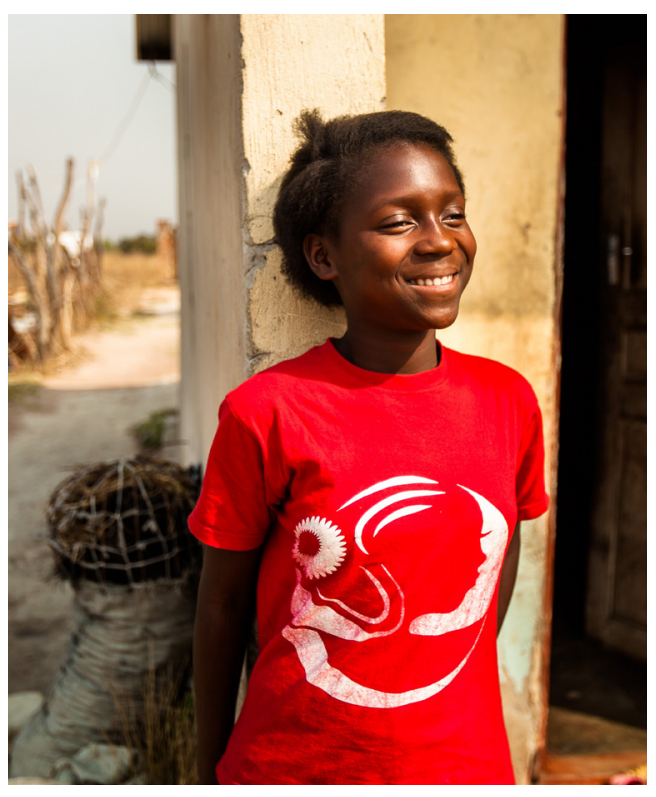

More than half of young Zambian women age 15-24 report having sex before age 18 , more than a third have experienced violence, and nearly half believe a man is justified in beating his wife if she talks back to him or neglects their children. (2013-14 Zambia Demographic and Health Survey)

\footnotetext{
${ }^{1}$ Amin, S., J. Ahmed, J. Saha, M. Hossain, and E. Haque. 2016. Delaying child marriage through community-based skills-development programs for girls: Results from a randomized controlled study in rural Bangladesh. New York and Dhaka, Bangladesh: Population Council.

2 Erulkar, A. and Muthengi, E. 2009. "Evaluation of Berhane Hewan: A program to delay child marriage in rural Ethiopia," International Perspectives on Sexual and Reproductive Health 35(1): 6-14.

${ }^{3}$ Bandiera, O., N. Buehren, R. Burgess, M. Goldstein, S. Gulesci, I. Rasul, and M. Sulaiman. 2012. Empowering Adolescent Girls: Evidence from a Randomized Control Trial in Uganda. Washington, DC: World Bank Group. http://documents. worldbank.org/curated/en/543691468309340444/Empowering-adolescent-girls-evidence-from-a-randomized-controltrial-in-Uganda
} 
Figure 1: Asset Building Theory of Change

\section{Asset Building Theory of Change}

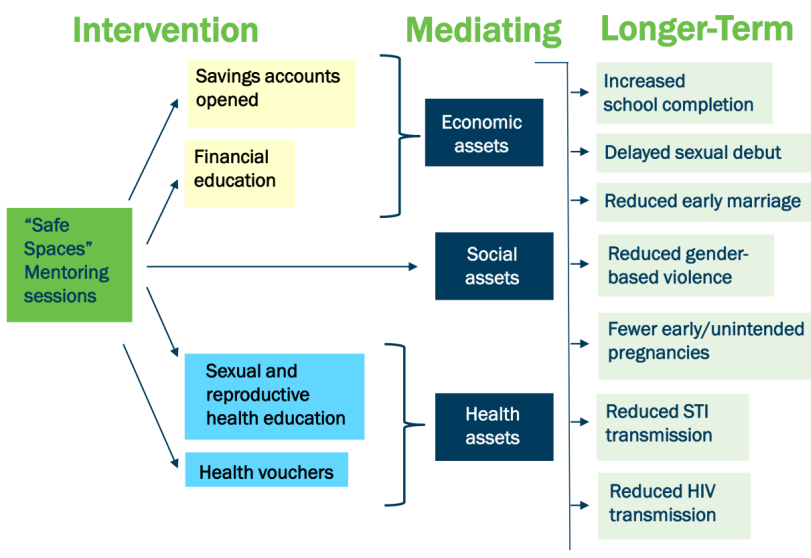

to build social, health and economic assets in the short term, there will be longer term dividends on health and education outcomes.

After a pilot period, AGEP rolled out in August 2013 to 11,000 girls living in 10 sites across four provinces. A household survey identified girls from lower-income backgrounds with multiple vulnerabilities: being out of or behind in school, without living parents, and/or physically or socially isolated. The most vulnerable girls were invited to participate ${ }^{4}$.

\section{Figure 2: Map of Program Sites}

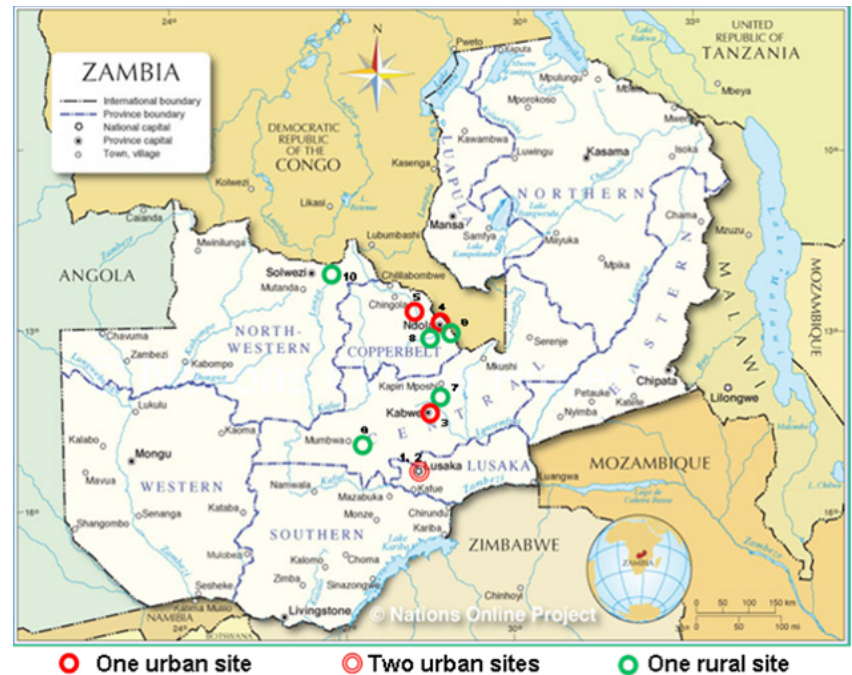

To determine the impact of AGEP on mediating and longer-term demographic, reproductive, and health outcomes, researchers designed, implemented and evaluated three program components in the form of a longitudinal, randomized controlled trial.

${ }^{4}$ http://www.popcouncil.org/uploads/pdfs/2016PGY_AGEP-Vulnerability_brief.pdf

\section{PROGRAM COMPONENTS}

\section{Safe Spaces}

In partnership with YWCA Zambia, AGEP created a platform of girls groups, each made up of 20 to 30 girls that met weekly in every program site for the duration of the two years. Groups were structured in age cohorts of 10-14 and 15-19, with additional groups for married girls and girls with children to ensure appropriate programming and sessions were facilitated by a mentor, a trained woman from that community. Groups met in a designated community space - schools, churches, homes or under a tree.

These sessions, the core of the intervention, were a way to educate girls on sexual and reproductive health, nutrition, and life skills while they gained social assets such as friendships, trusting relationships and self-esteem. Safe-spaces mentors also delivered financial education and saving training, often relating savings to health and personal empowerment, such as reducing the need for transactional sex to obtain money for food or other necessities.

Mentors were an important element, if not the key, to the program: they were role models, the sole providers of the program's educational content and the main point of contact with the girls and their families. They monitored and encouraged each girl's participation and also organized parent/husband and community meetings about the program to foster support for it.

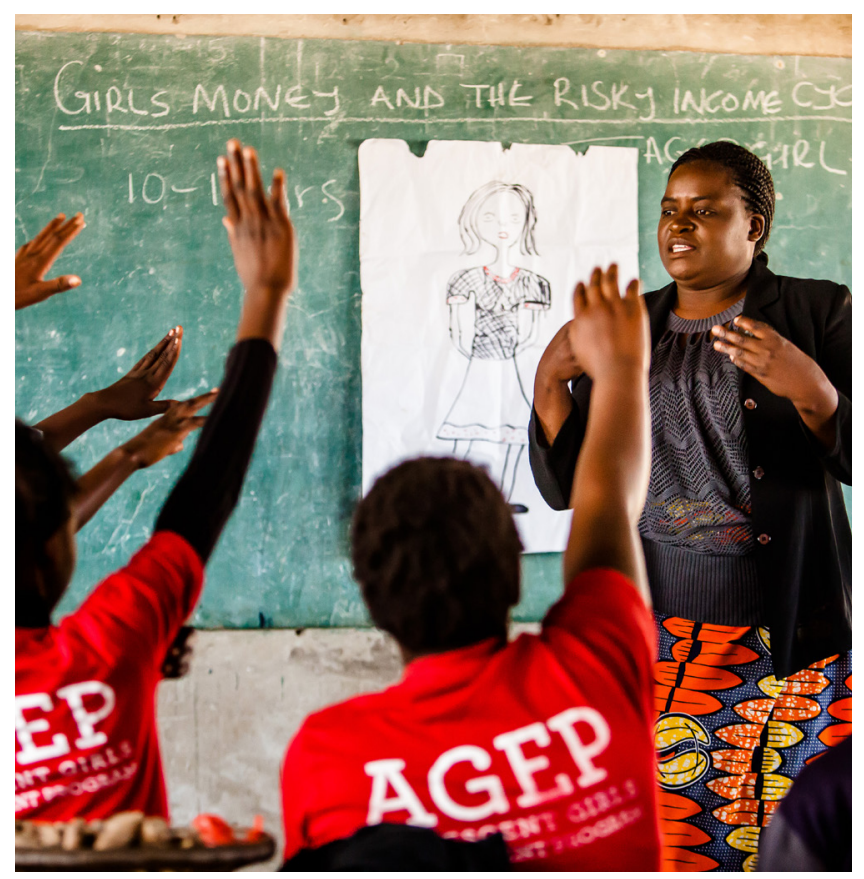




\section{Savings Accounts}

The Population Council partnered with Natsave and Making Cents International to develop the Girls Dream Savings Account for AGEP participants. This adolescent-friendly account had a very low minimum opening balance and no fee for deposits or withdrawals. Account opening was done during the safe spaces groups and girls were taken to the nearest bank branch for a sensitization visit. Any participant under age 18 needed to enlist a female adult as a co-signer on the account that would assist with account opening and withdrawals. The aim of the savings account was to motivate savings behavior, reinforce learning from the financial education training and provide girls with a safe, formal place to store their savings.

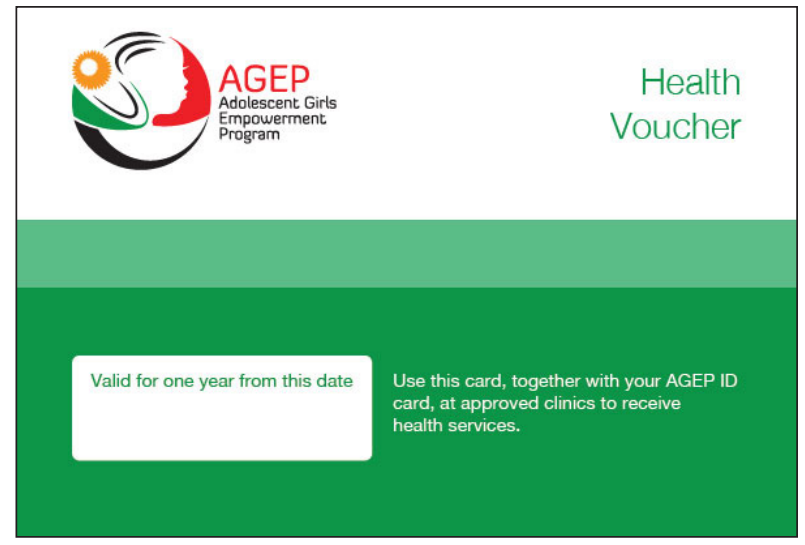

\section{Health Vouchers}

In partnership with the Government of Zambia (GRZ) and InSTEDD, the Council developed and provided health vouchers that AGEP participants could redeem for a package of health services at contracted public and private health providers. Providers would send in the service and voucher codes via SMS, which linked to a cloud-based system that recorded the transactions.

Services included basic wellness exams, general illnesses (diarrhea, malaria, etc.), counseling and age-appropriate sexual and reproductive health care. Providers were trained to make their services adolescent-friendly, with assurances of privacy and confidentiality. The aim of the health voucher was to improve the supply of adolescent-friendly health services and to increase the demand for health services among adolescent girls by removing financial barriers and increasing their sense of entitlement to access services.

\section{EVALUATION DESIGN}

To evaluate AGEP's impact, researchers embedded a randomized controlled trial with four years of observation. Council researchers followed the selected girls through the two-year intervention period and will continue for two years afterward. Baseline line data collection was implemented in 2013, with annual follow-up in 2014 and 2015; ongoing surveys will take place in 2016 and 2017.

Each community was randomly assigned to receive either the full program (safe spaces, savings accounts and health vouchers), or a partial version: safe spaces with health vouchers, or safe spaces only. A fourth arm served as a control arm where no program components were provided. In this randomized cluster design, each group was compared with each other, as well as a control group.

Figure 3: Research Design

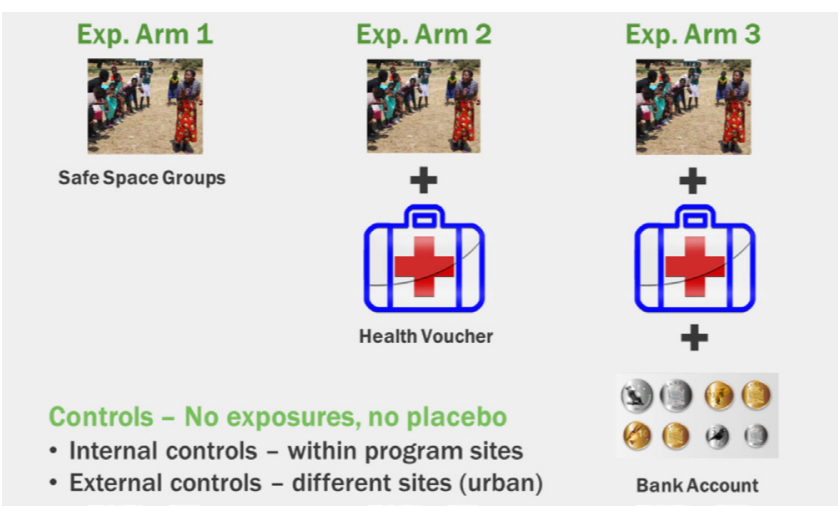

The mid-term assessment, immediately after the end of the AGEP intervention, includes three rounds of a survey with 5,235 girls who were not married at baseline. The survey measured a range of empowerment and longer-term adolescent outcomes, including self-esteem, social networks, work and savings activity, nutrition status, numeracy and literacy skills, cognitive function, sexual and reproductive health knowledge, sexual behavior, and attitudes and behaviors related to gender. Girls age 15 or above were tested for HIV and HSV-2. The study was able to track 90 percent of the baseline sample in both the second and third rounds of data collection.

The evaluation design also included a sub-study to evaluate the impact of nutrition education integrated into the safe spaces curriculum, on anemia, dietary diversity and anthropometric growth of adolescent girls and their children. The sub-study findings will be published in 2018 in a separate paper. 


\section{PRELIMINARY FINDINGS}

IMPACT: Overall, while there was positive change observed in each of the asset categories of empowerment, as well as some health behaviors, the degree of change vis-à-vis both the baseline levels and the breadth of indicators measured was more modest then expected. Across the age and location groups, AGEP was found most effective for rural girls under age 15 and within the first year of the program.

Immediately after the end of the program, AGEP girls had higher levels of sexual and reproductive health knowledge as well as greater access to safe places in the community apart from home and school. In addition, girls in the program showed a boost of self-efficacy and self-confidence in decisionmaking, achieving goals and managing problems. However, the latter two changes were significant only for the program's first year.

All the girls' financial literacy rose steadily over the full period. The program also increased the likelihood they had saved, and the amount of money saved, and this was an even stronger effect for girls in the savings account arm.

AGEP girls are less likely to be having transactional sex and more likely to use a condom during their first sexual experience. However, there was no change as of yet in longer terms outcomes, such as age of sexual initiation; experiences of violence; or rates of unintended pregnancy, sexually transmitted infections, including HIV and HSV-2, or education outcomes.

One of the more telling findings was that regressive norms about the roles of girls and boys, women and men, as well as the common perception that a husband is often justified in hitting his wife remained static throughout the study period. This finding points to the intractable nature of these core beliefs and the need for broader program efforts to address gender norms.

PARTICIPATION RATE: An important observation from the program was on the ability to recruit and retain vulnerable girls over the two-years. Overall, of the girls invited to participate, only 30 percent attended half or more of the AGEP meetings; some 46 percent attended fewer than half of the sessions and 24 percent never attended at all. Girls who were under 15, living in rural areas, and the biological daughters of heads of household were the most likely to take part. They were more willing and able than older and urban girls to invest the time and travel effort to attend, perhaps valuing the program's novelty in
At the end of the program, AGEP girls engaged in less transactional sex and used a condom more at their first sexual experience in comparison to the control girls. However, gender norms remained unchanged.

an area where such things were otherwise scarce. Older girls also had more demands on their time from household, caregiving, and labor responsibilities.

VOUCHER USE: Overall, one in five girls who received a voucher redeemed it for health services. On average, each girl who used the voucher used it for two services, Approximately three-quarters of the services redeemed were for general health services such as treatment of diarrhea, malaria or respiratory tract infections. Older girls were more likely to make use of SRH services, and over 80 percent of girls who used a SRH service also accessed a general health service, perhaps suggesting that general health services could be a bridge into SRH services. Usage was particularly lacking among the youngest girls age 10-15, most likely because younger adolescents are generally healthy and not yet sexually active. Other barriers to care included crowded or distant facilities and social stigma for adolescents who seek reproductive health or family planning services.

SAVINGS ACCOUNT USE: About half of girls in communities randomized to receive savings accounts were able to complete the account opening-process, with the figure going up to three-quarters of girls who actively participated. About a third of girls who opened accounts transacted on the account after account opening. However, having an account was a motivator for girls to save - informally and formally - as girls with savings accounts were more likely to save, and in higher amounts, compared to those without a savings account.

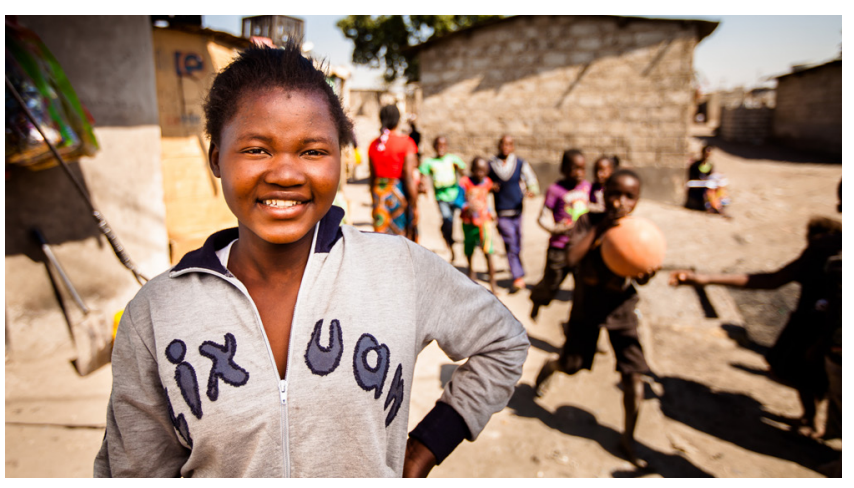




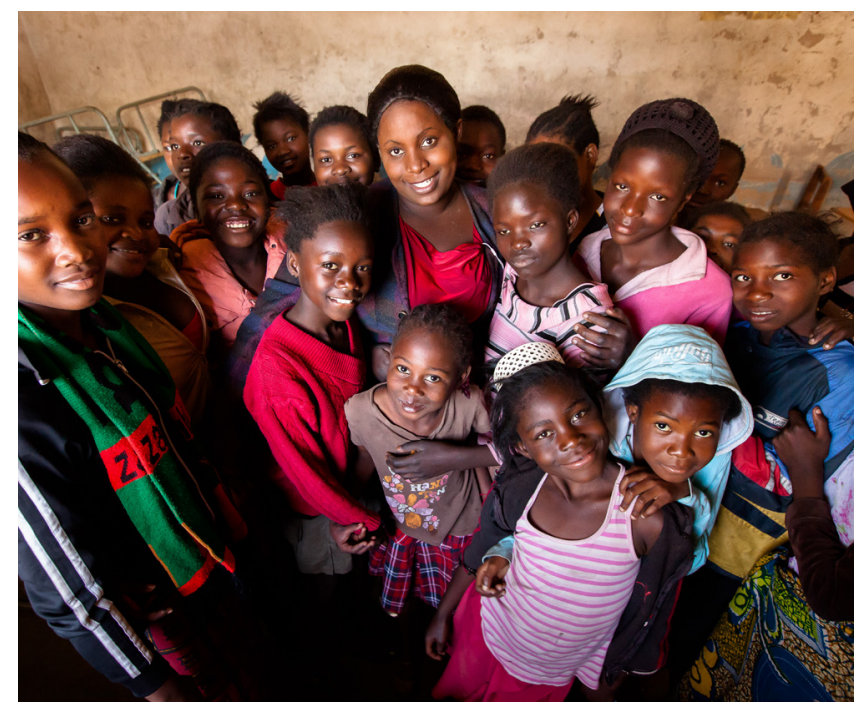

\section{BEYOND AGEP}

The AGEP impact findings raise many questions about the interplay between established social norms and interventions that are new to these girls and their communities. While the interventions have shown effectiveness in other countries, the results in Zambia on empowerment and impact indicators did not provide compelling evidence that safe spaces and girls' asset-building on their own would lead to the impacts laid out in the theory of change within two years' time.

Important to note is that the study is continuing for two additional years and was designed to observe these changes over the full four years. It remains to be seen as the AGEP girls experience a different empowerment trajectory and, as they continue to age and undergo more adolescent transitions, whether AGEP's impact will be observed more fully in the longer term.

The project findings point to the potential benefits of engaging girls early -- as young as 10 and before age 15 - and increasing their visibility in and access to community resources via the safe spaces platform. The findings also highlight the challenges for young girls in communities with deep-rooted norms relating to gender equality, behavioral expectations, and sexual/gender-based violence. This suggests that the direct-to-girls platform, while a necessary component of reaching vulnerable girls, is not sufficient in the Zambian context to overcome the range of individual, household, and community-level factors preventing a safe, healthy, and productive transition into adulthood.
As evaluations of AGEP's long-term impact continue, these short-term results suggest the need for programs that:

- Couple the safe spaces groups with an "ecological" approach to working with girls to involve parents, boys and young men, and key community members. On its own, safe spaces may have a limited impact in the Zambian context.

- Address social and cultural norms around gender roles and adolescent sexuality, including use of SRH services, at individual, household, community and even national levels.

- Take into account the specific needs of sub-groups of very vulnerable girls, who may not participate in general safe spaces programs, as shown by their participation uptake in AGEP, and design targeted interventions that address those needs. For example:

- Encourage more formal education support for girls to remain in school.

- Link knowledge and skills to work opportunities and access to resources to enhance the effect of interventions.

- Consider the trade off between a theory of change that focuses on a wide range of topics, but does not provide depth on any one of the, such as AGEP, versus one that focuses on a narrower range of outcomes, but provides more depth.

The direct-to-girls platform is a necessary component of reaching vulnerable girls, but is not sufficient in the Zambian context to overcome the range of individual, household, and community community-level factors preventing a safe, healthy and productive transition into adulthood.

For more information about the Adolescent Girls Empowerment Program please visit: http://www.popcouncil.org/research/ adolescent-girls-empowerment-program 


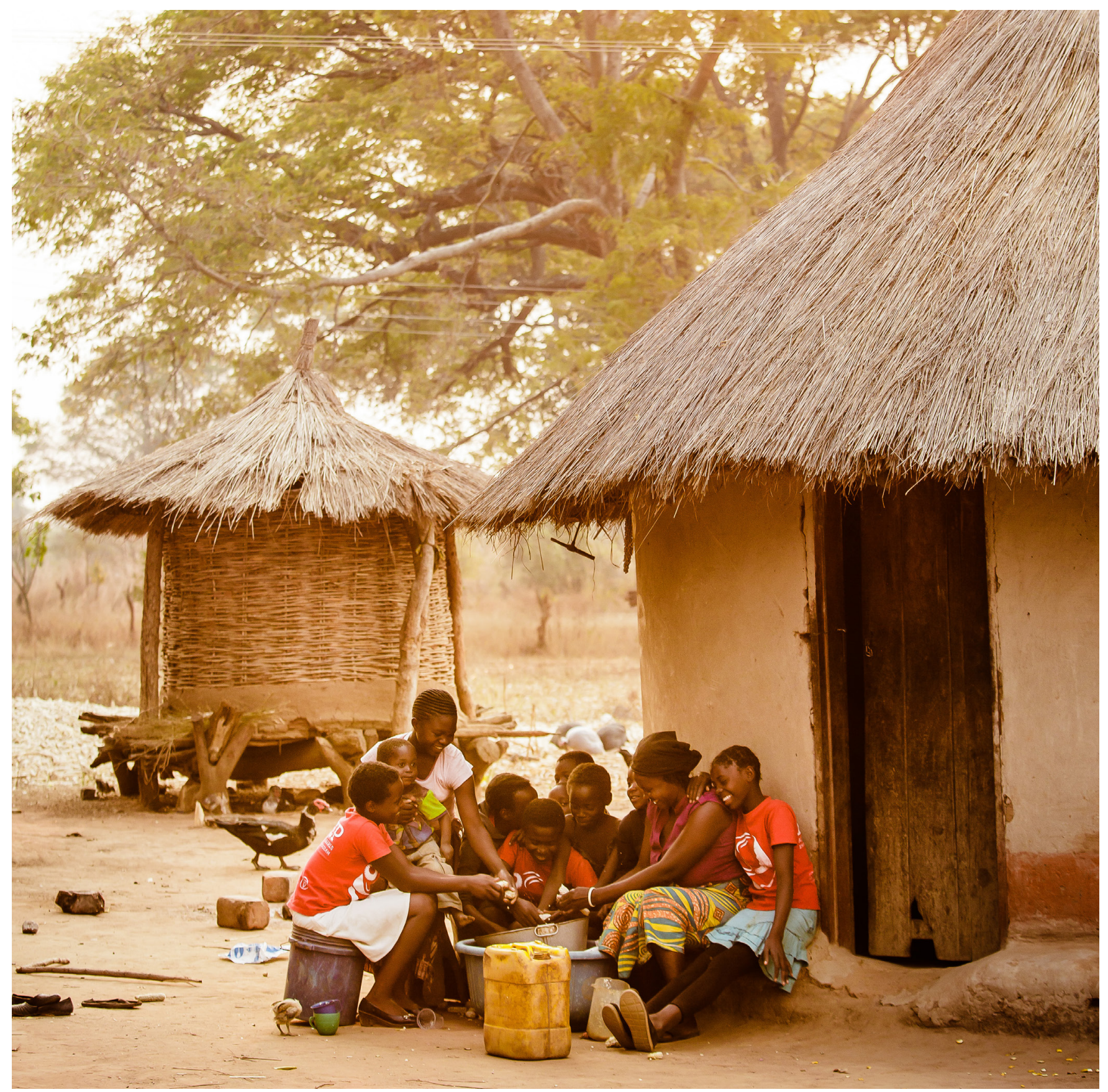

Population Council, Zambia

Plot 3670, No. 4

Mwaleshi Road, Olympia Park

Lusaka, Zambia

Tel: +260 211295925

email: info.zambia@popcouncil.org

Photos: John Healey
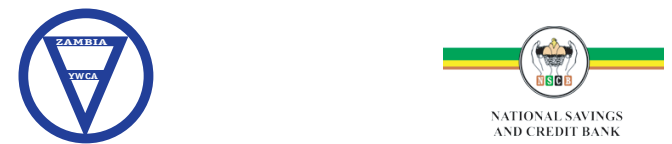

UKaid

POPULATION
COUNCIL
Ideas. Evidence. Impact. 